\title{
A Survey on Impact of Bio-inspired Computation on Stock Market Prediction
}

\author{
Smruti Rekha Das ${ }^{1}$, Debahuti Mishra ${ }^{2}$ and Minakhi Rout ${ }^{1}$ \\ Department of Computer Science and Engineering, Siksha 'O'Anusandhan University, Bhubaneswar, Odisha, INDIA \\ Department of Information Technology, GNITC, Hyderabad, INDIA
}

Received 13 April 2017; Accepted 15 July 2017

\begin{abstract}
Financial forecasting is one of the imperative fields of research, where investors invest money and get restless for the future changes of the stock values in the market. In the recent course of time forecasting stock price is one of the challenging tasks. To predict the stock price most Artificial Neural Network (ANN) based model are used in the historical data along with statistical measures, technical indicators etc. With the development of ANNs, investors are hoping the best prediction because networks have great capability of machine learning problems such as classification and prediction. ANNs particularly Back Propagation (BP) has overlooked the non-stationary and noise characteristics of stock market data, as the training of BP is intricate due to the noise data and the network fall into a natural solution such as always predict an usual output. Most optimization techniques have been used for training the weights of forecasting models. Since no single optimization technique is invariably superior to others. Recently various nature inspired optimization techniques have been introduced and successfully employed to many fields of Financial Engineering. This survey aims to study the mostly used Bio-inspired optimization techniques on Stock Market Prediction and makes a comparative analysis between them.
\end{abstract}

Keywords: Bio - inspired, Stock Market, impact

\section{Introduction}

Stock market forecasting is a hottest field of research due to its market volatility. Volatility generally refers to the statistical measure of the dispersion of returns for a given market index or security. It is measured either by using variance in between returns or by using the standard deviation returns from that same market index or security. Due to its volatile nature the fluctuations of price is unpredictable most of the times, for which the investor has to face a severe loss. If we can predict accurately the price of stock, then we can take good decisions and can be successful in meeting our goals and objectives. Prediction or we can say forecast is a statement about an uncertain event, but forecasting is not about predicting the market rather marketing the prediction. In order to predict stock market, this is basically the method to determine the prospective value of the company's stock or any other financial instrument which is traded on an exchange. This prediction of the stock's upcoming price, if successful, could result in relevant profit. It is official for the stock market investor to take more precise and informed investment decision, so for this, finding more productive prediction methods for stock market index is an absolute necessity. Therefore, stock market prediction has always had issue for researchers and the problem in prediction lies in the complexities of modeling of the share market dynamics [1]. Predictive

\footnotetext{
*E-mail address: das.smrutirekha13@gmail.com

ISSN: $1791-2377$ @ 2017 Eastern Macedonia and Thrace Institute of Technology. All rights reserved. doi:10.25103/jestr.103.15
}

analysis can be implemented to any type of unspecified event, irrespective of when it occurs. There are two classes of predictive models broadly classified into: non-parametric and parametric, and a third class i.e., semi-parametric models which include both the features. In case of predictive modeling, at first the data is assembled for significant predictors then a statistical model is devised, afterword predictions are prepared and the model is validated as soon as additional data is available. The model may involve a complex neural network or a simple linear equation. Among the literature utilizing the prediction tool, majority of them focus [2] on Artificial Neural Network(ANN), Back Propagation Neural Network(BPNN) but again back propagation(BP) is distinguished due to poor convergence, hence various enhancement for BP, such as quick propagation algorithm etc. are developed. Parameters optimization machining is one of the most vital and fascinating problems in the world of manufacturing. The complexity in the optimization [3] models causes the upcoming proposition of several new optimization techniques to resolve them. Prime optimization techniques comprise of Genetic Algorithms (GA), Simulation Annealing, Ant Colony Optimization (ACO), Particle Swarm Optimization (PSO), Differential Evolution (DE) etc. Here in this paper application of assorted optimization techniques for the stock market prediction is analyzed. All the optimization techniques are having its own benefit and restriction. Practical application of some of the techniques on stock market prediction is envisioned. The introduction of some of the techniques is compiled here with a little description. PSO is a population based [4] optimization technique, which can be linked to the behavior of flock of 
birds and so many improvements, has been done incorporating to the existing equations of PSO. Basing on the foraging behavior of the E. Coli and M. Xanthus Bacteria Foraging Optimization (BFO) is [5] developed and the algorithm models [6] bacterial population chemotaxis, swarming, reproduction, elimination and dispersal. GA is an intelligent probabilistic [7] search algorithm which can be applied to combinatorial optimization problem. It is a family of computational model [8] inspired by evolution. DE is a heuristic approach introduced by Storn and Price to minimize the [9] nonlinear and non differentiable function. For each individual [10] in the population, offspring is created using a weighted difference of the parent solution. ACO inspired from [11] the foraging behavior of some ant species, where a number of artificial ants can build solution by exchanging information on their quality. Artificial Bee Colony (ABC) is based on [12] the intelligent behavior of honey bee swarm. Cat Swarm Optimization (CSO) is based [13] on the inspecting behavior of the cat which is having two sub modes [14] one is seeking mode and another is tracing mode. Cuckoo Search is meta-heuristic method based [15] on the obligate brood parasitic behavior of some cuckoo species. BAT is a novel algorithm inspired by [16] the behavior of bats. Artificial Fish Swarm Algorithm (AFSA) is developed by observing long on the fish nature using the swarm intelligence basing [17] on the imitating behavior of the fish such as preying, swarming etc. Bioinspired algorithms, consisting both Evolutionary computing and Swarm Intelligence takes into account the communal behavior of dispersed and self organizing nature of existing home ground and this concept is implemented to arrive at a sub-optimal solution from all feasible solutions.

The rest of the survey is organized as follows: Section 2 discusses the application of various optimization techniques in the prediction model with a comparative study and a summary of the bio-inspired algorithms is drawn in conclusion, in the last section.

\section{Literature Survey}

\subsection{BFO}

As the small investors can also get good profit by investing money in stock market, hence it is known to be a profitable area by the investors. A great attention has been devoted by the researchers to analyze and predict the future value in financial market. Due to the non-volatility and nonstationary characteristics, it has become not only a great challenge but also difficult to forecast an accurate model. Even distinct financial forecasting methods with its own merits and demerits have been analyzed in different literatures. Across the globe a number of researches have been done in the area of stock market prediction. Broadly there are three grass level thoughts, the [1] first one is above trading average cannot be achieved by any investors basing on both historical and present information thoughts. The second one is the fundamental analysis which undergone through various macro economic factors. It focuses on the evolution of accurate prices [18] of stocks and the expected return from those stocks. Most often the company circumstances and the economic environment are the factor that is used to analyze the stock prices. The third view is the technical analysis phase which uses technical indicators which are the statistical parameters and chatting patterns from historical data. For forecasting financial data the recent model has been developed which is broadly divided into two categories such as statistical models and soft computing models. From the statistical[19] approach regression, correlation, spectral analysis etc. and from the soft computing approach such as ANN, Fuzzy logic, Support Vector Machine(SVM), evolutionary computation etc are employs to develop stock forecasting model.

So many evolutionary computing tool has been developed to update in trading the weights of forecasting models and here Ritanjali Majhi et al. reported a model [1] based on BFO to predict stock index movements, It can be applicable for both short term and long term prediction. BFO is a nature inspired algorithm developed by Passino on the basis of foraging behaviour of Bacteria. The basic steps for executing BFO are Chemo taxis, Reproduction, Elimination and Dispersal. Various parameters of BFO has used in the simulation study and the prediction performance of BFO is found better as compared to MLP based standard forecasting model. As to the algorithm of BCO (Bacteria Chemotaxis Optimization) the searching will be ensnared into local extreme. To overcome from this the Improved $\mathrm{BCO}(\mathrm{IBCO})$ has been designed by Zhang Yudong et al., who has emphasized[20] on ANNs particularly BP which overlooked the noise and the statistical properties, which is not constant over time of stock market data, as the training of BP is intricate due to the noise data. Here the IBCO is incorporated with BP network to predict stock index for both short term (next day) as well as long term (15days). The IBCO optimization techniques is used for weight updating and found that the simulation result of IBCO-BP model is better than BP model. It offers better accuracy, less computational complexity and less training time. The IBCO differs from BCO by separating in to two stages one is infra colony phase and the other one is inter colony phase. But for certain problem the designer has contented with local optimal solutions, hence a novel hybrid approach model has designed by Dong Hwa Kim consisting of GA and BF [21] having potential to solve the practical optimization problem. For this here S\&P 500 stock index data has gathered to train BP neural network, taking 2350 trading days and the inputs are the opening price, closing price, high value, low value along with some technical indicators. The model calculate the computational time for 1 day, 3 days, 5 days, 7 days, 9 days and 15 days prediction in advance for S\&P 500 . It found that IBCO-BP model is giving better prediction result than the traditional BP model. But again to keep away the limitations of neural network model or any hybrid neural network Rudra Kalyan Nayak et al. proposed an easy [22] and more resilient hybridized frame work of SVM and K Nearest Neighbour (KNN) algorithm which gives better results with greater prediction accuracy.

Unlike conventional BFO, in fuzzy-BFO the performance measure depends on the choice of the membership functions. Hence the fuzzy-BFO presented by S.Mishra et al. found that the basic foraging strategy is made [23] adaptive through a Takagi-sugeno fuzzy scheme depending upon the operating condition to make the convergence faster. Introducing a better prediction model for short and long term prediction of stock indices Ritanjali Majhi et al. developed a[24] work which is a combination of $\mathrm{BFO}$ and Adaptive $\mathrm{BFO}(\mathrm{ABFO})$ algorithms. Its first aim is to combine the structure of model with BFO and its second aim is to apply ABFO on the same function to predict a efficient model. The prediction accuracy of this proposed 
model is much better than GA and PSO and it converges faster.

In the primary of BFO the chemotaxis step length is kept as a constant amount, but to balance the global search and local search here Ben Niu et al. anticipated a modified BFO where each bacterium kept as a good balance between exploitation and exploration [25] by decreasing its runlength unit linearly. Among the steps of BFO chemo taxis procedure is a key step.

Table 1: The findings of the model using BFO Optimization technique

\begin{tabular}{|c|c|c|c|}
\hline Domain & Sources of Data & Proposed model & Findings \\
\hline $\begin{array}{l}\text { Stock market } \\
\text { prediction }\end{array}$ & $\begin{array}{lrr}\text { S\&P } & 500 & \text { and } \\
\text { DJIE } & \text { stock } \\
\text { indices } & \end{array}$ & $\begin{array}{l}\text { Simulated } \\
\text { BFO model. }\end{array}$ & $\begin{array}{l}\text { Prediction } \\
\text { performance is } \\
\text { better as } \\
\text { compared with }\end{array}$ \\
\hline $\begin{array}{l}\text { Stock market } \\
\text { prediction }\end{array}$ & $\begin{array}{l}\text { Stock } \\
\text { exchange of } \\
\text { Thailand(SET) }\end{array}$ & $\begin{array}{l}\text { Main drive } \\
\text { indicators are } \\
\text { exposed using } \\
\text { Soft } \\
\text { computing } \\
\text { techniques and } \\
\text { non-soft }\end{array}$ & $\begin{array}{l}\text { Soft } \\
\text { computing } \\
\text { techniques are } \\
\text { having the } \\
\text { potential to } \\
\text { determine the } \\
\text { influence }\end{array}$ \\
\hline $\begin{array}{l}\text { Stock market } \\
\text { prediction }\end{array}$ & $\begin{array}{l}\text { S\&P } 500 \text { stock } \\
\text { index }\end{array}$ & $\begin{array}{l}\text { IBCO-BP } \\
\text { model. }\end{array}$ & $\begin{array}{l}\text { Better } \\
\text { prediction } \\
\text { result than the } \\
\text { troditinna1 }\end{array}$ \\
\hline $\begin{array}{l}\text { Stock market } \\
\text { prediction }\end{array}$ & $\begin{array}{l}\text { S\&P } \\
\text { DJIA, }\end{array}$ & $\begin{array}{l}\text { Using } \\
\text { adaptive } \\
\text { bacterial } \\
\text { foraging } \\
\text { optimization } \\
\text { (ABFO) and }\end{array}$ & $\begin{array}{l}\text { Performing } \\
\text { better } \\
\text { compared to } \\
\text { GA and PSO } \\
\text { model. }\end{array}$ \\
\hline $\begin{array}{l}\text { Portfolio } \\
\text { Management }\end{array}$ & & $\begin{array}{lr}\text { Portfolio } \\
\text { optimization } \\
\text { with } & \text { liquidity } \\
\text { risk } & \text { using } \\
\text { nгn r } & \end{array}$ & $\begin{array}{l}\text { BFO with linear } \\
\text { decreasing } \\
\text { chemo taxis step } \\
\text { obtains better }\end{array}$ \\
\hline
\end{tabular}

\subsection{PSO}

For making decision several factors or objectives is considered by stock traders, hence in order to standardize the efficiency of the studied trading system supported on multiobjective particle swarm optimization (MOPSO) Antonio C. Briza et al.[26] made a relative study with the performance of three widely accepted trading system like technical indicators, market and another stock trading system optimized with NSGA-II algorithm. Basically PSO is a population based stochastic optimization technique, inspired by social population of bird flocking or school fishing. The proposed Multi Objective Optimization trained intraday trading agents for an artificial market which encourages an application to end-of-day market data. Though Neural Network has been widely used to solve the decision making problems but again it suffers from black box and slow convergence. To avoid the black box problem Fuzzy logic is formulated which make a frame work of approximate reasoning and also can tolerate imprecise information. Over again fuzzy logic is having the lack of effective learning capability and to overcome these drawbacks Huang Fu-yuan et al. developed an Improved Particle Swarm Optimization algorithm (IPSO) combined with fuzzy logic and neural network and named [27] it as IPSO-FNN model. To overcome the draw backs of PSO that is having a higher convergence speed an improved PSO is proposed where the delta rule has been modified by including the momentum term. The performance of IPSO-FNN in predicting the accuracy is much higher than the result obtained from neural network. The daily closing price is just real number which is precise. Most of the method basing on fuzzy logic adopt Type-1 fuzzy sets representing uncertainties with the range between $[0,1]$ and type- 1 fuzzy sets is having a precise membership function where its elements are real number. To handle [28] this difficulties a type-2 fuzzy sets is introduced which is most able to handle the uncertainty related to noisy and non-stationary than type-1 fuzzy set along with allowing uncertainty [29-32] to its associated membership degree. For the prediction of stock price Chih-Feng et al. presented a type-2 neuro-fuzzy model where [28] a self constructed clustering method designed the type- 2 fuzzy rules and then refined it by a hybrid algorithm. To form a fuzzy rule base, the type-2 TSK is derived and then the hybrid learning algorithm incorporated PSO and least square estimating is used for the refinement of the parameters associated with the rules. Considering the non-linearities and discontinueous factors Daviv Enke et al. analyzed about the three stage stock market prediction, where in the first phase, it defines economic and financial variable which is having a strong relationship with its output, here multiple Regression Analysis is applied. In the second phase a prediction model is designed by a type- 2 fuzzy clustering optimized by $\mathrm{DE}$ and for the third phase to perform [33] the future reasoning a fuzzy type- 2 based neural network is used. The simulated result shows that the performance of the above three model is better than the traditional model. The chaotic nature of the financial data does not follow linearity, hence to handle this uncertainty and chaotic nature evolution computing methods like ANN, SVM, GA, PSO, BFO are designed which perform excellent compared to statistical approach. After a brief study of the existing work of different types of ANN, it is observed that Radial Basis Function Neural Network (RBFNN), Recurrent Neural Network (RNN), Multi Layer Perceptron (MLP) etc are the most popular neural network. But again Neural network Models suffer from Computational complexity, hence to overcome these limitations S.Chakravarty et al. presented a [34] a hybrid model of functional link and type-2 fuzzy logic system optimized by PSO, where it uses the TSK type fuzzy rule base that applies type-2 fuzzy sets in the antecedent part and FLANN in the consequent part. The above hybrid model is compared with two other models, one is integration of FLANN with type-1 fuzzy logic and another is Local Linear Wavelet Neural Network (LLWNN). The above three models are optimized through PSO giving better performance comparing with the limitations of BP algorithm which is having slower convergence and inability to escape from local optima.

For many years the forecasting and modeling of time series has been growing in the financial and economic literature, and the fluctuations of stock price following the principle of clustering is proved inefficient to perform accurate forecasting. Hence Jui-Chung Hung developed a PSO based adaptive Fuzzy-GARCH model [35] to solve this problem. PSO is used in order to get the optimal solution for the Fuzzy-GARCH model, where in the search space the 
trajectory of each particle is dynamically adjusted by the velocity of each particle.

The time series problem is quit complex and chaotic by nature; hence for response integration Martha Pulido et al. projected a neural network ensemble [36] with type-2 fuzzy logic. Here in this model, to obtain the best architecture of the ensemble neural network the PSO is used to determine the number of modules of the neural network, number of layers and number of neurons for layer. Here the model used the ensemble network which is a idea of joining multiple decisions and predicting better result. So many different financial forecasting models have been intoduced in the literature, each one of which has its own pros and cons. The SVM was first suggested by Vapnik has recently been used in a range of application using financial market prediction, hence M. Karazmodeh et al. implemented [37] Improved PSO in SVM for prediction of stock market. The results of solo SVM, SVM integrated with PSO and Improved PSOSVM (IPSOSVM) is taken, where in IPSOSVM, GA is introduced in to PSO and it is basically PSO with mutation. Results state that the mutation in particles led the accuracy being higher, since the particle always searches the whole state space which prevents the mistake of not finding the best options in other possible states.

Table 2: The findings of the model using PSO Optimization technique:

\begin{tabular}{|c|c|c|c|}
\hline Domain & Sources of & Proposed & Findings \\
\hline $\begin{array}{l}\text { Stock } \\
\text { market } \\
\text { prediction }\end{array}$ & & $\begin{array}{l}\text { Based on } \\
\text { MOPSO of } \\
\text { technical } \\
\text { indicators on } \\
\text { end-of-day } \\
\text { market data }\end{array}$ & 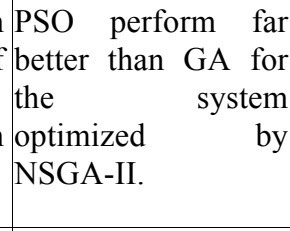 \\
\hline $\begin{array}{l}\text { Stock } \\
\text { market } \\
\text { prediction }\end{array}$ & $\begin{array}{l}\text { TAIEX and } \\
\text { NASDAQ }\end{array}$ & $\begin{array}{l}\text { Application of } \\
\text { type-2 neuro- } \\
\text { fuzzy modeling } \\
\text { in stock price } \\
\text { prediction }\end{array}$ & $\begin{array}{l}\text { Self constructed } \\
\text { clustering method to } \\
\text { design a type- } 2 \\
\text { fuzzy rule and then } \\
\text { refined by a PSO } \\
\text { based hybrid }\end{array}$ \\
\hline $\begin{array}{l}\text { Stock } \\
\text { market } \\
\text { prediction }\end{array}$ & $\begin{array}{l}\text { S\&P } \\
500, \text { BSE,DJIA }\end{array}$ & $\begin{array}{l}\text { A PSO based } \\
\text { FLIT2FNS } \\
\text { for stock } \\
\text { market } \\
\text { prediction }\end{array}$ & $\begin{array}{l}\text { FLIT2FNS performs } \\
\text { the best irrespective } \\
\text { of the time horizons } \\
\text { spanning from one } \\
\text { day to one month. }\end{array}$ \\
\hline $\begin{array}{l}\text { Stock } \\
\text { market } \\
\text { prediction }\end{array}$ & $\begin{array}{l}\text { Taiwan, } \\
\text { Nikkei225, } \\
\text { and Dax }\end{array}$ & $\begin{array}{l}\text { A PSO based } \\
\text { Adaptive } \\
\text { Fuzzy- } \\
\text { GARCH } \\
\text { model } \\
\text { applied to } \\
\text { forecasting }\end{array}$ & $\begin{array}{l}\text { A PSO based } \\
\text { Adaptive fuzzy- } \\
\text { GARCH model } \\
\text { performs better than } \\
\text { other } \\
\text { considering models } \\
\text { generated rules to }\end{array}$ \\
\hline $\begin{array}{l}\text { Stock } \\
\text { market } \\
\text { prediction }\end{array}$ & $\begin{array}{l}\text { Mexican stock } \\
\text { exchange }\end{array}$ & $\begin{array}{l}\text { PSO based } \\
\text { method for } \\
\text { designing } \\
\text { ensemble } \\
\text { neural } \\
\text { network with }\end{array}$ & $\begin{array}{l}\text { Comparing with } \\
\text { other optimization } \\
\text { technique, PSO a } \\
\text { meta heuristic } \\
\text { technique perform } \\
\text { very well in speed. }\end{array}$ \\
\hline
\end{tabular}

Stock $\quad$ DJI, S\&P 500 A hybrid An improved hybrid market and Nasdaq- model using IPSOSVM is used prediction 100 Support to predict the future prediction $100 \quad$ Vector movement of stocks Vector
Machines and and the Mutation in Improved particles led the Particle accuracy being Swarm higher. Ontimization

\subsection{GA}

Though Technical Analysis is a helpful method for forecasting stock prices but for non-professionals it is difficult to apply forecasting techniques as there is excessive number of complex technical indicators. Autoregressive moving average model (ARMA) and Autoregressive Conditional Heteroscedasticity(ARCH) are two statistical assumptions that are required to design forecast models of mathematical equations which is not easily understood by the stock investors. And secondly some artificial intelligence algorithm like neural network cannot be easily realized. To overcome from the above problem Ching-Hsue cheng hybridized four factors [38] into a single model. In the first factor the data transformation and the selection of essential technical indicator is performed. In the second factor it used cumulative probability distribution approach (CPDA) and Minimize Entropy Principle Approach (MEPA) to discretize technical indicators and daily price fluctuation. The basic purpose of MEPA is to find out the information available in the data set. In recent years MEPA is used for the forecasting problems, it is basically used to divide the data into membership functions where it establishes the point of segmentation between the classes of the data. In third factor it applies Rough Set Theory (RST) to discover trading rules. The fourth factor is Genetic Algorithm which is an evolutionary algorithm converging to global optimum in many applications. The steps of GA in the proposed model are reorganized as follows: Initialization, Evaluation, Check termination criteria, Selection according to best fitness value, Selection, Crossover, and Mutation.

Too many input variables for forecasting model causes over fitting and noise. To improve the above problem DengYiv Chiu proposed a new dynamic fuzzy model in combination with [39] SVM to look into stock market mechanism. The fuzzy model considering both micro economic variables and technical indicators adjusting with time, where GA determines the optimal parameters of Fuzzy model for each influence factor changing with time, and SVM will locate the relationships among influence variables. In this proposed model it shows that with GA the approximate optimal solution can be located and the better parameters of the model can be obtained in a certain period of time.

Though ANN is able to handle non-linear problems but again to overcome the limitations of Neural Network Hyun-jung Kim et al. look into the[40] effectualness of a hybridized approach based on the the time delay neural networks(TDNNs) and adaptive TNN(ATTNs) and with the genetic algorithms(GAs) in sleuthing temporal patterns for the task of prediction. Along with the several control design of ANN, extra memory for the time delayed link is added to ANN in case of TDNN and ATNN. Day by day forecasting stock market becomes difficult due to the high volatility of laws, here Md. Rafiul Hassan et al. proposed a [41] model which is a fusion of HMM, ANN and GA to forecast stock 
market. To predict time series phenomenon successfully HMM is a widely used tool and in this model ANN is used to transform the input observation sequences and GA is optimizes the initial parameters of the HMM. The optimized parameters are able to identify the similar patterns from the historical data set. The Efficient Market Hypothesis (EMH) maintains the current market price of a stock and reflects it to the traders. This hypothesis [42] implies that the future stock price cannot be evaluated from past stock price. Using all the computational tools available for analyzing time series and complex system Armano et al. introduced a hybrid model that integrates GAs and ANNs and exploit them for foresting the next-day price. This model proves a excellent prediction strategy for large data sets.

Table 3: The findings of the model using GA Optimization technique:

\begin{tabular}{|c|c|c|c|}
\hline Domain & Sources of & Proposed model & Findings \\
\hline $\begin{array}{l}\text { ock } \\
\text { ice } \\
\text { recasting }\end{array}$ & TSMC & $\begin{array}{l}\text { Rough } \\
\text { theory and GA } \\
\text { based hybrid } \\
\text { model used to } \\
\text { forecast stock }\end{array}$ & $\begin{array}{l}\text { The hybrid model } \\
\text { considering the } \\
\text { advantages of RST } \\
\text { and GE produce a } \\
\text { superlative results. }\end{array}$ \\
\hline $\begin{array}{l}\text { Stock } \\
\text { market } \\
\text { prediction }\end{array}$ & $\begin{array}{l}\text { Taiwan } \\
\text { Stock } \\
\text { Exchange }\end{array}$ & \begin{tabular}{|lr} 
Fuzzy & model \\
with & SVM \\
explored & stock \\
market & \\
dynamism & with \\
high input & space \\
nnd $\Omega \wedge$ &
\end{tabular} & $\begin{array}{l}\text { Integrating fuzzy } \\
\text { theory, GA and } \\
\text { SVM and applying } \\
\text { on Taiwan stock } \\
\text { market, found GA } \\
\text { performing better. }\end{array}$ \\
\hline $\begin{array}{l}\text { Stock } \\
\text { market } \\
\text { prediction }\end{array}$ & $\begin{array}{l}\text { Korea } \\
\text { Stock Price } \\
\text { Index } 200\end{array}$ & $\begin{array}{lr}\text { Hybridization of } \\
\text { ATNNs } & \text { and } \\
\text { TDNNs } & \text { with } \\
\text { GAs } & \text { in } \\
\text { detecting } & \\
\text { temporal } & \\
\text { nnttarns } & \text { fnr }\end{array}$ & $\begin{array}{l}\text { GA selected several } \\
\text { parameters, which } \\
\text { can greatly } \\
\text { influence the } \\
\text { optimization of the } \\
\text { algorithm. }\end{array}$ \\
\hline $\begin{array}{l}\text { Stock } \\
\text { market } \\
\text { prediction }\end{array}$ & $\begin{array}{l}\text { COMIT, } \\
\text { S\&P } 500\end{array}$ & $\begin{array}{l}\text { A hybrid } \\
\text { genetic-neural } \\
\text { architecture for } \\
\text { stock indexes } \\
\text { forecasting }\end{array}$ & $\begin{array}{l}\text { Hybrid model tested } \\
\text { for COMIT and S\&P } \\
500 \text {, found superior } \\
\text { result compared to } \\
\text { B\&H strategy for } \\
\text { large test set }\end{array}$ \\
\hline
\end{tabular}

\subsection{ACO}

In recent years forecasting stock market is a very challenging as well as beneficial issue, as more and more people are investing their money in financial market. Researchers are analyzing various methods and techniques to propose prediction model as it is highly essential according to the dynamics of the market. Basing on this scenario Salah Bouktif et al. recommend an ensemble technique based on ACO combine with Bayesian classifier. ACO is a biological evolving algorithm simulating the [43] foraging behavior of ants. The above proposed model basically preserves the interpret ability of the model, as it is very critical to detect the state and scores of mood that cause a movement of a particular stock, and the stock market movement varies on the attributes representing the public mood, which is collected from the social network. Here the prediction model is proposed with four approaches including bagging and boosting. The model is learned from the data which is collected publicly from the social side network and the model is able to find good prediction accuracy and simultaneously preserves model interpret ability. The combinatorial complexity that arises in the solution is helped by an ACO algorithm, which is customized for combining Bayesian Classifiers. From the previous study it shows Neural network is performing extremely good in the prediction of non linear dynamic system, then in this aspect neural network is a very good method to forecast stock market but in mathematic aspect, the laws that are hidden in the stock market data is considered. Here the laws are function relationship and basing on this mathematic description W. Gao proposed a new evolutionary neural network model, which is verified by real stock market data in 1996. In this proposed evolutionary neural network [44] model its weight are confirmed by Multiple Back Propagation Algorithm and the construction of this model is confirmed by ACO algorithm. After computation it found that neural network construction 7-13-1 is best for stock index forecasting and 9-21-3 is the best neural network construction for daily turnover. Here the development law of stock market is described properly. Again the non linear dynamism of the stock market is influenced by various factors such as market expectation, policy and financial condition. The collective effect of these three factors vantage to highly complex random variation of the stock price. In order to get the better of this short comings Xiao-yu Fang et al. projected wavelet transform as preprocessor of SVM to get rid of fluctuant element of input data and apply ACO algorithm[45] for the optimization of the parameters of SVM. Here the improved ACO is applied, differs from original ACO, which arrived from path optimization problem.

Table 4: The findings of the model using ACO Optimization technique:

\begin{tabular}{|c|c|c|c|}
\hline Domain & Sources of & Proposed model & Findings \\
\hline $\begin{array}{l}\text { Stock } \\
\text { Market } \\
\text { Prediction }\end{array}$ & $\begin{array}{l}\text { User mood } \\
\text { measurements } \\
\text { from Twitter } \\
\text { and Facebook }\end{array}$ & $\begin{array}{l}\text { Basing on the } \\
\text { mood collected on } \\
\text { Twitter, } \\
\text { application of } \\
\text { ACO for }\end{array}$ & $\begin{array}{l}\text { Model proves better } \\
\text { prediction accuracy } \\
\text { than the model } \\
\text { derived } \\
\text { alternative }\end{array}$ \\
\hline $\begin{array}{l}\text { Stock } \\
\text { Market } \\
\text { Prediction }\end{array}$ & $\begin{array}{l}\text { Shangai } \\
\text { Market } \\
1996\end{array}$ & $\begin{array}{l}\text { Forecasting } \\
\text { Financial Data } \\
\text { based on BP } \\
\text { al marithm }\end{array}$ & $\begin{array}{l}\text { Performs very well } \\
\text { to real practice. }\end{array}$ \\
\hline $\begin{array}{l}\text { Stock } \\
\text { Market } \\
\text { Prediction }\end{array}$ & $\begin{array}{l}\text { Huaneng } \\
\text { Guoji stock }\end{array}$ & $\begin{array}{l}\text { SVM using } \\
\text { Wavelet } \\
\text { Transform as a } \\
\text { preprocessor and } \\
\text { ACO }\end{array}$ & $\begin{array}{l}\text { ACO-SVM with } \\
\text { wavelet transform } \\
\text { had achieved best } \\
\text { forecasting price. }\end{array}$ \\
\hline
\end{tabular}

\subsection{DE}

Stock market prediction is an important area of research, where in so many applications considered BPNN as a familiar learning algorithm, but a few researchers used DE as an optimization criterion. Here Lin Wang et al. used DE for taking the initial weights and [46] threshold in the forecasting of time series data. It is same as GA using the same operator but the basic difference between them is DE relies on mutation operator while GA relies on crossover operator. Considering DE Mustafa E. Abdul_Salam et al. made a comparison study between DE and PSO applying on [47] training of Feed-Forward Neural Network (FFNN) for 108 
than PSO. Here for the input layer FFNN has taken six technical indicators. In essence DE optimizes the values of the Network weights. The engrossing point about DE's replacement is that a trial vector produced after applying the cross over is only compared to one individual instead all individual of the current population. Here both DE and PSO avoid local minima problem and converge to a global minimum but again in case of Time series data DE performing better than PSO. Various fluctuated time series data sets like ACADIA, SHLO, FTWR, HYZ, NET, CALPER has been taken for training as well as for testing the network by dividing training part into $70 \%$ and testing part into $30 \%$ and found that, though both converge to global minimum but DE converges faster than PSO.

Marketing people need predictions to meet the expectations. Prediction is not only confined to stock market, it can be made for various things like prediction of protein level, weather forecasting, mutual fund prediction, gold price forecasting, oil price prediction, Rubber price prediction, vegetable price prediction etc. Among the above prediction stock market prediction, Exchange rate prediction and gold price prediction are very chaotic in nature, so it is a very challenging issues as its needs very fast decisions for making the computational cost of the market. Accurate prediction of various exchange rates is essential as significant amount of trading takes place through the currency exchange rate. Minakhi Rout et al. developed a model for forecasting the exchange rate using [48] the (Auto Regressive Moving Average) ARMA model trained by DE. ARMA is a statistical based method which is having some limitations. To avoid these limitations, soft and evolutionary computing based method is hybridized with ARMA architecture for forecasting of exchange rate. Easy statistical characteristic are extracted for each exchange rate using a sliding window of past data and are made use of as input to the prediction model using DE optimization strategy for training its internal coefficients. The result of the above hybrid model is compared with the other competitive optimization technique such as ARMA-BFO, ARMS-CSO, ARMA-PSO and ARMA-Forward Backward Least Mean Square (FBLMS). The simulation results show ARMAFBLMS is performing worst prediction performance and ARMA-DE outperforms all other similar hybrid model. Financial market prediction is seems to be more and more complex as various social and economic phenomena lead to a high degree [49] of uncertainty. Barberis and Thaler [50] and Hirshleifer [51] comprise a large study of activity of Finance. Indeed various studies recommended that investor persuasion and trading activities of noise traders influence stock prices a lot. Nizar Hachicha [49] looks for an explanation of price dynamics by considering the fundamental explanatory variables and the behavioral approach. To satisfy the price dynamic Nizar Hachicha used fuzzy sets optimized through DE, where DE is used to optimize the strength of Fuzzy inference operators, at the same time the tuning of membership functions and fuzzy rules. The implication of the above model is done by taking the data of international market (Paris stock exchange market) which seems to be the efficient one and an emergent one (Tunis stock exchange market) considered as the inefficient one. The data has been employed from the period of 1999 to 2005. Again considering the degree of efficiency two portfolios is considered one is a banking sector portfolio and the other one is the non banking sector. So it gives rise to four portfolios for return modeling, these are portfolio for return in Emergent Banking, portfolio for return in Emergent Non Banking, portfolio for return in an International Banking and portfolio for return in an International Non Banking. Comparing the performance of the proposed methodology with the traditional logic concerning both banking and non banking return sector of both emergent and international market and at the same time optimizing the membership functions and fuzzy rules, it can judge the efficiency degree of each portfolio as well as of each market. DE [52] is an efficient population based search engine, is placed to optimize the tuning parameters required to build the predictive system. DE is having five stages: initialization, mutation, crossover, selection and stopping condition. DE has applied [53] as the optimizer to search for LS-SVM optimum parameters. DE follows a non-uniform cross over which takes child vector parameters from one parent [54] more often than it takes from others. Puspanjali Mohapatra et al. developed a FLANN based model optimized with DE by taking the Indian Stock Prices, predicting the stock price indices for one day, one week, two week and one month ahead, found FLANN trained with DE is giving good result. It compares the result with FLANN trained with BP, though both are giving good prediction performance but again FLANN_DE gives significantly better result. It proves it by taking $\bar{R}$ MSE and MAPE values during testing for one day, one week, two week, and one month in advance.

Table 5: The findings of the model using DE Optimization technique:

\begin{tabular}{|c|c|c|c|}
\hline Domain & Sources of & Proposed & Findings \\
\hline $\begin{array}{l}\text { Stock } \\
\text { Price } \\
\text { Prediction }\end{array}$ & $\begin{array}{l}\text { ACADIA, } \\
\text { SHLO, } \\
\text { FTWR, } \\
\text { HYZ, NET, } \\
\text { CALPER }\end{array}$ & $\begin{array}{l}\text { A comparison } \\
\text { study between } \\
\text { PSO and DE } \\
\text { in training of } \\
\text { FFNN in stock } \\
\text { price } \\
\text { nmantinn }\end{array}$ & $\begin{array}{l}\text { PSO performing better } \\
\text { than DE in case of } \\
\text { accuracy, handling } \\
\text { fluctuated stock time } \\
\text { series and converge } \\
\text { speed. }\end{array}$ \\
\hline $\begin{array}{l}\text { Exchange } \\
\text { rate } \\
\text { prediction }\end{array}$ & \begin{tabular}{l|} 
Indian \\
Rupees, \\
British \\
pound, \\
Japanese Yen
\end{tabular} & $\begin{array}{l}\text { Exchange rate } \\
\text { prediction } \\
\text { using adaptive } \\
\text { ARMA } \text { with } \\
\text { DE r based } \\
\text { training. }\end{array}$ & $\begin{array}{l}\text { ARMA-DE performs } \\
\text { better than ARMA- } \\
\text { BFO, ARMA-CSO, } \\
\text { ARMA-PSO, ARMA- } \\
\text { FBLMS. ARMA- } \\
\text { FBLMS is having }\end{array}$ \\
\hline $\begin{array}{l}\text { Stock } \\
\text { price } \\
\text { Prediction }\end{array}$ & $\begin{array}{lr}\text { Paris } & \text { stocks } \\
\text { change } & \text { market } \\
\text { and } & \text { Tunis } \\
\text { stocks } & \text { change } \\
\text { market } & \end{array}$ & $\begin{array}{l}\text { Modeling the } \\
\text { financial } \\
\text { market } \\
\text { dynamics by } \\
\text { a fuzzy logic } \\
\text { control using } \\
\text { diffarantin1 }\end{array}$ & $\begin{array}{l}\text { It performs efficiently } \\
\text { in the account of } \\
\text { dynamic emergent and } \\
\text { International Financial } \\
\text { market. }\end{array}$ \\
\hline $\begin{array}{l}\text { Stock } \\
\text { Price } \\
\text { Prediction }\end{array}$ & $\begin{array}{l}\text { Stock } \\
\text { Exchange of } \\
\text { Thailand } \\
\text { during } 2003 \text { to } \\
2006\end{array}$ & $\begin{array}{l}\text { Application of } \\
\text { Self } \\
\text { DE Adaptive } \\
\text { Forecasting of } \\
\text { Thailand Stock }\end{array}$ & $\begin{array}{l}\text { The proposed model } \\
\text { performing } \\
\text { compared }\end{array}$ \\
\hline
\end{tabular}




\begin{tabular}{|c|c|c|c|}
\hline $\begin{array}{l}\text { Stock } \\
\text { price } \\
\text { prediction }\end{array}$ & $\begin{array}{l}\text { BSE, } \\
\text { INFY }\end{array}$ & NSE, $\begin{array}{lr}\text { A } & \text { DE based } \\
\text { Neural } & \\
\text { Network } \\
\text { approach for } \\
\text { the } & \text { Prediction } \\
\text { of } & \text { Indian } \\
\text { Stock } & \text { Market. }\end{array}$ & $\begin{array}{l}\text { DE optimized FLANN } \\
\text { is giving better result } \\
\text { compared with the } \\
\text { FLANN trained with } \\
\text { BP. }\end{array}$ \\
\hline
\end{tabular}

\subsection{AFSA}

To bring about accurate forecasting result researchers have applied so many techniques. Here a Forecasting model using Radial Basis Function Neural Networks optimized by AFSA is developed by Wei Shen et al. [55], where the proposed model is executed on the data of Shanghai Composite Indices. AFSA[56] is a artificial intelligent algorithm inspired by swarm intelligence. Initially [55] the behavior of a single artificial fish is simulated then make a swarm of artificial fish. Each artificial fish search its own local optimum and pass on the information to achieve the global optimum. The behavior of fish swarm is having five behaviors :(i) searching behavior, (ii) Swarming behavior, (iii) Following behavior, (iv) Behavior selection, (v) Bulletin. In this proposed[55] model the number of hidden units of RBF is initialized by taking the population of artificial fish colony, the adjustment of center behavior denotes the swarming behavior of $\mathrm{AF}$, weights of RBF is updated with the searching behavior of AF, in behavior selection it compares the results of the center adjustment with the previous iteration and update the optimum result and in Bulletin it compares the food concentration with that on the bulletin and replace the state if the result is better. Result shows that the prediction accuracy of RBF optimized with AFSA improved to some extents as compared with GA and PSO. Dongxiao Niu[57] proposed a hybrid model RBF optimized by AFSA, where before training the data is under gone for pretreatment of reduction to unity and found the result is relatively good both in trend fitting and accuracy. Basing on Radial basis function as a kernel function $\mathrm{Ma} \mathrm{Li}$ et al. developed a Support Vector Regression(SVR) machine[58] optimized by AFSA, where exchange rate data is considered to predict the sixth day by considering the five days as a cycle. Here two parameters of SVR, one is penalty factor and another is Kernel variance are optimized by AFSA, gives optimal accuracy and better convergence speed.

Table 6: The findings of the model using AFSA Optimization technique:

\begin{tabular}{|c|c|c|c|}
\hline Domain & Sources of Data & Proposed model & Findings \\
\hline $\begin{array}{l}\text { Stock } \\
\text { market } \\
\text { prediction }\end{array}$ & $\begin{array}{l}\text { Shanghai } \\
\text { Composite } \\
\text { Indices }\end{array}$ & $\begin{array}{l}\text { Learning } \\
\text { process of RBF } \\
\text { optimized by } \\
\text { AFSA used to } \\
\text { predict rtock }\end{array}$ & $\begin{array}{l}\text { RBF optimized with } \\
\text { AFSA, applying to } \\
\text { closing price } \\
\text { prediction gives } \\
\text { better performance }\end{array}$ \\
\hline $\begin{array}{l}\text { Short term } \\
\text { forecast of } \\
\text { Stock } \\
\text { indices }\end{array}$ & $\begin{array}{l}\text { Sganghai Stock } \\
\text { Exchange }\end{array}$ & $\begin{array}{l}\text { A } \\
\text { approach wherid } \\
\text { RBF optimized } \\
\text { using AFSA. }\end{array}$ & $\begin{array}{l}\text { For both in trend } \\
\text { finding } \\
\text { accuracy and } \\
\text { performance the } \\
\text { AFSA with RBF is } \\
\text { better. }\end{array}$ \\
\hline
\end{tabular}

\begin{tabular}{|c|c|c|c|c|}
\hline $\begin{array}{l}\text { Forex } \\
\text { prediction }\end{array}$ & $\begin{array}{l}\text { State } \\
\text { administration of } \\
\text { Foreign } \\
\text { exchange and } \\
\text { RMB exchange } \\
\text { middle rate }\end{array}$ & $\begin{array}{l}\text { Prediction } \\
\text { FOREX } \\
\text { on } \\
\text { optimized } \\
\text { AFSA }\end{array}$ & $\begin{aligned} & \text { of } \text { Comparing } \\
& \text { basing } \text { other } \\
& \text { SVR } \text { competing } \\
& \text { by } \text { optimization } \\
& \text { methods: } \\
& \text { GASVR }\end{aligned}$ & $\begin{array}{l}\text { with } \\
\text { three }\end{array}$ \\
\hline
\end{tabular}

\subsection{ABC Optimization Technique}

Numerous factors influence stock market prediction and also several studies have shown that ANN outperforms, but considering some of disadvantages of ANN where enormous difficulties is faced for interpreting the results due to its black-box techniques. Tsung-jung Hsieh et al. [59] presented a integrated model where Recurrent Neural Network (RNN) and Wavelet Transforms that are based on ABC algorithm are combinedly used for stock market prediction. The $\mathrm{ABC}$ algorithm is a new-heuristic approach proposed by Basturk and Karaboga[60] and further developed in various stage[61-63]. It is inspired by the intelligent foraging behavior of Honey bee swarms. The foraging bees are classified into three categories employed, onlookers and scouts. Employed and onlooker bees exploit the source where as the scout bees explore the source. The employed bees collect the loads of nectars and put it in the hives; the onlookers wait in the hives for the employed bees and collect information about the source from the employed bees. The way of transferring the information is through dance of employed bees. The employed bees dance in a common area of hives called dance area. The frequency of dance is proportional to the content of identified source. Before choosing a food source the onlookers have to watch numerous dances. Once a food source has been fully exploited the scout explores the new source. A scout or an onlooker become employed whenever it finds a food source. The proposed method[60] is tested on the data set Taiwan Stock Exchange(TAIEX) but the simulation studies is done by taking data of other international stock market i.e. DJIA, FTSE and Nikkei-225. As the time series data are volatile, hence Wavelet transform is used to filter the data. Wavelet approach is flexible in handling the highly irregular data series. Wavelet transforms not only decompose the data in terms of time and frequency but also reduce the processing time. The basic work of Wavelet is to preprocess the data as the data are available in various scales. RNN is applied here to create the input features chosen by Stepwise RegressionCorrelation Selection (SRCS), and then ABC is used to update the weights of RNN. Basically RNN is having three control parameters, which includes the number of employed or onlooker bees, the value of limit and the Maximum Cycle Number $(\mathrm{MCN})$. Considering these parameters the weights and biases of the RNN is optimized. In the same way Esmail Nourani et al. developed [64] an integrated system where the data are preprocessed by using haar wavelet transform and then applied on ANN, which is trained through two phases: first phase is $\mathrm{ABC}$ algorithm and the second phase is Levenberq-Marquardt algorithm. ABC algorithm is used to optimize the weights of ANN; the result proved the above hybrid method is a promising method in comparison with standard ABC algorithm, GA and different variations of BP algorithm. $\mathrm{ABC}$ is having the advantages [65] of memory, local search, multi characters and a solution improvement mechanism. Identifying this quality Minakhi Rout et al. proposed a model using a simple adaptive linear combiner, whose weights are trained by using $\mathrm{ABC}$ algorithm. The 
model is applied on the data S\&P 500 and DJIA and found better prediction value compared to ALC with PSO and GA. Another work of stock trends prediction is done by Rodrigo C.Brasileiro et al. where a combination of technical analysis, $\mathrm{ABC}$, selection of past values, nearest neighbor classification and its variation [66] and the adaptive classification and nearest neighbor is taken to measure the profitability in the analyzed period. ABC algorithm optimizes the parameters of the classifier. Experiments were performed using fifteen stocks and found outperforms that of Teixeira and Oliveira [67] 13 out of 15 stocks and is better than the buy and hold strategy in 14 out of 15 stocks. For more about $\mathrm{ABC}$ Zuriani Mustaffa et al. introduced a enhanced ABC hybridizing it with [68] Least square support vector machine (LS-SVM) to forecast the stock prices. Enhanced ABC introduced two modifications one is Levy mutation to enhance bee's exploitation process and the other one is simple mutation to prevent premature convergence.

Table 7: The findings of the model using ABC Optimization technique:

\begin{tabular}{|c|c|c|c|}
\hline Domain & Sources of & Proposed model & Findings \\
\hline $\begin{array}{l}\text { Stock } \\
\text { Market } \\
\text { Prediction }\end{array}$ & $\begin{array}{l}\text { Taiex, } \\
\text { djia, FTSE- } \\
\text { 100,Nikkei- } \\
225\end{array}$ & $\begin{array}{l}\text { Forecasting } \\
\text { Stock Market } \\
\text { by using } \\
\text { integration of } \\
\text { Wavelet } \\
\text { transforms and } \\
\text { RNN based on } \\
\text { ABC algorithm. }\end{array}$ & $\begin{array}{l}\text { ABC-RNN is } \\
\text { sufficiently robust and } \\
\text { having the satisfactory } \\
\text { predictive performance. }\end{array}$ \\
\hline $\begin{array}{l}\text { Stock } \\
\text { Price } \\
\text { Prediction }\end{array}$ & $\begin{array}{l}\text { Tehran Stock } \\
\text { Exchange }\end{array}$ & $\begin{array}{l}\text { Integrated } \\
\text { system formed } \\
\text { by Harr wavelet } \\
\text { transform data } \\
\text { preprocessing } \\
\text { based on ABC } \\
\text { algorithm to }\end{array}$ & $\begin{array}{l}\text { The training of ANN } \\
\text { after finishing ABC } \\
\text { phase and Levenberq- } \\
\text { Marquardt phase gives a } \\
\text { promising result } \\
\text { compared with other } \\
\text { tested algorithms. }\end{array}$ \\
\hline $\begin{array}{l}\text { k Market } \\
\text { Prediction }\end{array}$ & $\begin{array}{l}\text { S\&P } \\
\text { DJIA }\end{array}$ & $\begin{array}{lr}\text { ABC } & \text { based } \\
\text { ALC to predict } \\
\text { stock market } \\
\text { indices }\end{array}$ & $\begin{array}{l}\text { ALC-ABC performs } \\
\text { better compared to } \\
\text { ALC-GA and ALC- } \\
\text { PSO. }\end{array}$ \\
\hline $\begin{array}{l}\text { Stock } \\
\text { trend } \\
\text { prediction }\end{array}$ & $\begin{array}{lr}\text { Sao } & \text { Paulo } \\
\text { Stock } & \text { Market }\end{array}$ & $\begin{array}{l}\text { Automatic } \\
\text { method } \\
\text { combining } \\
\text { Technical } \\
\text { Analysis and } \\
\text { ABC for Stock }\end{array}$ & $\begin{array}{l}\text { For the strategies of buy } \\
\text { and hold this proposed } \\
\text { method performed well } \\
\text { comparing to other } \\
\text { methods. }\end{array}$ \\
\hline
\end{tabular}

\subsection{CSO, Bat, Cuckoo Search Optimization Technique}

Forecasting activities of Stock Market is generally divided into three categories that is short term, medium term and long term. Short term forecasting involves a few minutes, hours or days within a week, a medium term forecasting is above one week and within a month and a long term forecasting covers the periods of one to few years. Though a numerous studies and research have been focused on ANN for finding stock market forecasting but here Ms.K.Nirmala Devi proposed a CS-SVM (Cuckoo Optimized SVM) applying on Stock Market [69] prediction. Cuckoo search [70] follows three idealized rules (1) At a time only one egg is laid by a Cuckoo, and dump its egg in randomly choosen nest; (ii) The best nest with high quality of eggs will carry over the next generation; (iii) The number of available host nest is fixed, and the probability of host bird to discover the egg laid by the cuckoo is Pa $\in[0,1]$. Here [69] CS-SVM is used to select the best features of $\mathrm{C}$, $\sigma$ and $\varepsilon$ in SVM and the fitness function is the Error rate: Error rate=100-Accuracy. The data set which is used for this model are BSE-Sensex and CNX-Nifty from January 2013 to July 2014. The result of SVM provides higher accuracy with lower MAPE and MSE compared to ANN and SVM. A novel CS model is proposed by Yanhong [70] with considering the specific advantages of levy flights and frog-leap operator. Levy walk around [69] the best solution will speed up the local search. A comparison study between so many [71] optimization techniques for Stock Market Forecasting is discussed by Osman Hegazy et al., where some are the recent bio-inspired algorithms which are namely Bat algorithm (BA), Modified Cuckoo Search (MCS), Flower Pollination Algorithm (FPA), Particle Swarm Optimization (PSO) and Artificial Bee Colony (ABC). LS-SVM (Least square- Support Vector Machine) and ANN are used as bench mark for comparison. Here S\&P 500 stock market data has been taken for prediction of daily, weekly and monthly stock price and found that the model is able to achieve better accuracy than ANN and LS-SVM. Among so many bio-inspired algorithm Bat algorithm is a metaheuristic algorithm based [72] on the echolocation behavior of the bat. Bat sends signals with loudness of frequency towards the object and when the signal deflects back [73] after striking the object; it calculates the distance from bat to any object and flies towards the minimum distance of object. Hafezi et al. proposed a new intelligent model in multi agent framework called BNNMAS(Bat-Neural-Network Multi Agent System) to predict[74] stock market. In multi agent system the agent team aimed at creating ANN trained by BATs, hence the team consists of Neural Network designing and bat designing algorithm. Where it used six neurons neural network and trained the normalized data with the bat algorithm. The model is implemented by taking the DAX data consisting of 30 major German companies, which is able to cope the fluctuation of stock Price. As Bats [75] are the extremely interesting animal, it advanced capability of echolocation have drawn the attention of researchers from various fields. Here Alberto Ochoa et al. Shows BAT algorithm significantly increased the understanding obtaining the best financial trust forest. As the time series data are chaotic and non-linear by nature, hence satyasai Jagannath Nanda designed a WNN-CSO (Wavelet Neural Network-Cat Swarm Optimization) model for [76] its accurate forecasting. CSO has been developed by viewing [77] the common behavior of cats. Somehow it belongs to swarm intelligence but again the weighting factor of CSO gives better result as compared to PSO. CSO is having two modes one is seeking mode and another is tracing mode. Joining of these two modes called Mixture ratio (MR) solves the optimization problem. It determines the number of cats to operate in seeking and tracing mode. It is a population [78] based learning rule and performs well in the presence of non-linearity in the plant. The performance of the WNNCSO is[76] compared with three bench mark model(i)WNNPSO[79], (ii) Chebyshev FLANN[80], (iii) MLP-BP[81] and found that in comparison with WNN_PSO, MLP-BP and Chebyshev FLANN; WNN-CSO performs superior in terms of response matching. Though Chebyshev FLANN is faster 
than the other model but WNN-PSO gives accurate results by sacrificing the computational time.

\section{Conclusion}

This paper surveyed an application of various optimization techniques, in use for the parameters optimization of respective models for the prediction of stock market indices. Its gives emphasized basically over BFO, PSO, GA. ACO, DE, ABC, AFSA, Cuckoo Search, CSO, BAT algorithm. All are having its own strong points on their ain field of application. Among the above optimization techniques BFO is performing better as it's having maximum number of parameter which is easy to symbolize with the parameters of stock market indices. From this survey it can be drawn to close that evolutionary computing performs well in the derivative based techniques in all fields, where as bioinspired techniques are controlled by social behavior of bionic family and they are more restive towards the noisy and non-stationary data.

This is an Open Access article distributed under the terms of the Creative Commons Attribution Licence

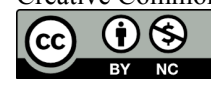

\section{References}

[1] R. Majhi, G. Panda ,G. Sahoo, P. K. Dash, D. P. Das, “Stock market prediction of S\&P 500 and DJIA using bacterial foraging optimization technique", IEEE congress on evolutionary computation, pp. 2569-2575, Sep 2007.

[2] S. Asadi, E. Hadavandi, F. Mehmanpazir, M. M. Nakhostin, “ Hybridization of evolutionary Levenberg-Marquardt neural networks and data pre-processing for stock market prediction", Knowledge-Based Systems, vol. 35, pp. 245-258, Nov 2012.

[3] S. Xie, Zhang Z. Zhang. "Models and Optimization Techniques of Machining Parameters in Turning Operations", Computational Methods for Optimizing Manufacturing Technology: Models and Techniques: IGI Global, pp. 162-192, 29 Feb 2012.

[4] F. Van den Bergh, A. P. Engelbrecht, "A cooperative approach to particle swarm optimization", IEEE transactions on evolutionary computation. vol. 8, no. 3, pp. 225-39, Jun 2004.

[5] Y. Liu, K. M. Passino, "Biomimicry of social foraging bacteria for distributed optimization: models, principles, and emergent behaviors", Journal of Optimization Theory and Applications. vol. 115, no. 3, pp. 603-28, Dec 2002.

[6] Y. Shi, (editor.), Innovations and Developments of Swarm Intelligence Applications. IGI Global, 31 May 2012.

[7] J. E. Beasley, P. C. Chu, "A genetic algorithm for the set covering problem”, European Journal of Operational Research. vol. 94, no. 2, pp. 392-404, 25 Oct 1996.

[8] D. Whitley, "A genetic algorithm tutorial", Statistics and computing, vol .4, no. 2, pp. 65-85, 1 Jun 1994.

[9] R. Storn, K. Price, "Differential evolution-a simple and efficient heuristic for global optimization over continuous spaces", Journal of global optimization, vol. 11, no. 4, pp. 341-59, 1 Dec 1997.

[10] J. Vesterstrom, R. Thomsen, "A comparative study of differential evolution, particle swarm optimization, and evolutionary algorithms on numerical benchmark problems", Evolutionary Computation, 2004. CEC2004. Congress on, vol. 2, pp. 1980-1987, IEEE, 19 Jun 2004.

[11] M. Dorigo, M Birattari, T. Stutzle, "Ant colony optimization", IEEE computational intelligence magazine. vol. 1, no. 4, pp. 28-39, Nov 2006.

[12] D. Karaboga, B. Basturk, "A powerful and efficient algorithm for numerical function optimization: artificial bee colony (ABC) algorithm", Journal of global optimization. vol. 39, no. 3, pp. 45971, 1 Nov 2007.

[13] S. C. Chu, P. W. Tsai, J. S. Pan, "Cat swarm optimization", Pacific Rim International Conference on Artificial Intelligence, Springer Berlin Heidelberg. pp. 854-858, 7 Aug 2006.

[14] P. W. Tsai, J. S. Pan, S. M. Chen, B. Y. Liao, S. P. Hao, “ Parallel cat swarm optimization", International Conference on Machine Learning and Cybernetics, IEEE, vol. 6, pp. 3328-3333, 12 Jul 2008.

[15] A. Kaveh, "Cuckoo Search Optimization", Advances in Metaheuristic Algorithms for Optimal Design of Structures, Springer International Publishing, pp. 321-352, 2017.

[16] P. W. Tsai, J. S. Pan, B. Y. Liao, M. J. Tsai, V. Istanda, "Bat algorithm inspired algorithm for solving numerical optimization problems", Applied Mechanics and Materials, Trans Tech Publications, vol. 148, pp. 134-137, 2012.
[17] S. Farzi, "Efficient job scheduling in grid computing with modified artificial fish swarm algorithm", International Journal of computer theory and engineering, Vol. 1, no. 1, pp. 13, Apr 2009.

[18] S. Chaigusin, C. Chirathamjaree, J. Clayden, "Soft computing in the forecasting of the stock exchange of Thailand (SET)", Management of Innovation and Technology, ICMIT 2008, 4th IEEE International Conference on 2008 Sep 21, pp. 1277-1281.

[19] R. Majhi, G. Panda, G. Sahoo, A. Panda, A. Choubey, "Prediction of S\&P 500 and DJIA stock indices using particle swarm optimization technique" IEEE Congress on Evolutionary Computation (IEEE World Congress on Computational Intelligence), pp. 1276-1282, 1 Jun 2008.

[20] Y. Zhang, L. Wu, "Stock market prediction of S\&P 500 via combination of improved BCO approach and BP neural network", Expert systems with applications, vol. 36, no. 5, pp. 8849-8854, 31 Jul 2009.

[21] D. H. Kim, A. Abraham, J. H. Cho, "A hybrid genetic algorithm and bacterial foraging approach for global optimization" Information Sciences, vol. 177, no. 18, pp. 3918-3937, 15 Sep 2007.

[22] R. K. Nayak, D. Mishra, A. K. Rath, "A Naïve SVM-KNN based stock market trend reversal analysis for Indian benchmark indices", Applied Soft Computing. vol. 35, pp. 670-80, 31 Oct 2015.

[23] S. Mishra, "A hybrid least square-fuzzy bacterial foraging strategy for harmonic estimation", IEEE Transactions on Evolutionary Computation, vol. 9,no. 1,pp. 61-73, Feb 2005.

[24] R. Majhi, G. Panda, B. Majhi, G. Sahoo, "Efficient prediction of stock market indices using adaptive bacterial foraging optimization (ABFO) and BFO based techniques", Expert Systems with Applications, vol. 36, no 6, pp. 10097-10104, 31 Aug 2009.

[25] B. Niu, Y. Fan, H. Xiao, B. Xue, "Bacterial foraging based approaches to portfolio optimization with liquidity risk", Neurocomputing, vol. 98, pp. 90-100, 3 Dec 2012.

[26] A. C. Briza, P. C. Naval, "Stock trading system based on the multiobjective particle swarm optimization of technical indicators on end-of-day market data", Applied Soft Computing, vol. 11, no. 1, pp. 1191-1201, 31 Jan 2011.

[27] F. Y. Huang, "Integration of an improved particle swarm algorithm and fuzzy neural network for Shanghai stock market prediction", Power Electronics and Intelligent Transportation System, 2008, Workshop on 2 Aug 2008, pp. 242-247..

[28] C. F. Liu, C. Y. Yeh, S. J. Lee, “Application of type-2 neuro-fuzzy modeling in stock price prediction", Applied Soft Computing, vol. 12, no. 4, pp. 1348-1358, 30 Apr 2012.

[29] R. I. John, P. R. Innocent, M. R. Barnes, "Neuro-fuzzy clustering of radiographic tibia image data using type 2 fuzzy sets", Information Sciences, vol. 125, no. 1, pp. 65-82, 30 Jun 2000.

[30] O. Mendoza, P. Melín, O. Castillo, "Interval type-2 fuzzy logic and modular neural networks for face recognition applications", Applied Soft Computing, vol. 9, no. 4, pp. 1377-1387, 30 Sep 2009.

[31] M. Singh, S. Srivastava, M. Hanmandlu, J. R. Gupta, "Type-2 fuzzy wavelet networks (T2FWN) for system identification using fuzzy differential and Lyapunov stability algorithm", Applied Soft Computing, vol. 9, no. 3, pp.977-989, 30 Jun 2009.

[32] M. H. F. Zarandi, M. Zarinbal, M. Izadi, "Systematic image processing for diagnosing brain tumors: A Type-II fuzzy expert 
system approach", Applied soft computing, vol. 11, no. 1, pp. 28594, 31 Jan 2011

[33] D. Enke, M. Grauer, N. Mehdiyev, "Stock market prediction with multiple regression, fuzzy type-2 clustering and neural networks", Procedia Computer Science, vol. 6, pp. 201-206, 1 Jan 2011.

[34] S. Chakravarty S, P. K. Dash, "A PSO based integrated functional link net and interval type-2 fuzzy logic system for predicting stock market indices", Applied Soft Computing, vol. 12, no. 2, pp. 931941, $29 \mathrm{Feb} 2012$.

[35] J. C. Hung, "Adaptive Fuzzy-GARCH model applied to forecasting the volatility of stock markets using particle swarm optimization". Information Sciences, vol. 181, no. 20, pp. 4673-83, 15 Oct 2015.

[36] M. Pulido, P. Melin, O. Castillo, "Particle swarm optimization of ensemble neural networks with fuzzy aggregation for time series prediction of the Mexican Stock Exchange", Information Sciences, vol. 280, pp. 188-204, 1 Oct 2014.

[37] M. Karazmodeh, S. Nasiri, S. M. Hashemi, "Stock price forecasting using support vector machines and improved particle swarm optimization", Journal of Automation and Control Engineering, vol. 1, no. 2, pp. 173-176, Jun 2013.

[38] C. H. Cheng, T. L. Chen, L. Y. Wei, "A hybrid model based on rough sets theory and genetic algorithms for stock price forecasting", Information Sciences, vol. 180, no. 9, pp. 1610-1629, 1 May 2010.

[39] D. Y. Chiu, P. J. Chen, "Dynamically exploring internal mechanism of stock market by fuzzy-based support vector machines with high dimension input space and genetic algorithm", Expert Systems with Applications, vol. 36, no. 2, pp. 1240-1248, 31 Mar 2009.

[40] H. Kim, K. Shin, "A hybrid approach based on neural networks and genetic algorithms for detecting temporal patterns in stock markets", Applied Soft Computing, vol. 7, no. 2, pp. 569-576, 31 Mar 2007.

[41] M. R. Hassan, B. Nath, M. Kirley, "A fusion model of HMM, ANN and GA for stock market forecasting", Expert Systems with Applications, vol. 33, np. 1, pp. 171-80, 31 Jul 2007.

[42] G. Armano, M. Marchesi, A. Murru, "A hybrid genetic-neural architecture for stock indexes forecasting". Information Science, vol. 170, no. 1, pp. 3-33, 18 Feb 2005.

[43] S. Bouktif, M. A. Awad, "Ant colony based approach to predict stock market movement from mood collected on Twitter", Advances in Social Networks Analysis and Mining (ASONAM), IEEE/ACM International Conference on 2013 Aug 25, pp. 837-845.

[44] W. Gao, "New neural network based on ant colony algorithm for financial data forecasting. InIntelligent Information Hiding and Multimedia Signal Processing", IIHMSP'08 International Conference on 2008 Aug 15, IEEE, pp. 1437-1440.

[45] X. Fang, T. Bai, "Share price prediction using wavelet transform and ant colony algorithm for parameters optimization in SVM", InIntelligent Systems, 2009. GCIS'09. WRI Global Congress on 19 May 2009, IEEE, vol. 3, pp. 288-292.

[46] L. Wang, Y. Zeng, T. Chen, "Back propagation neural network with adaptive differential evolution algorithm for time series forecasting", Expert Systems with Applications, vol. 42, no. 2, pp. 855-863, 1 Feb 2015.

[47] M. E. Abdual-Salam, H. M. Abdul-Kader, W. F. Abdel-Wahed, "Comparative study between Differential Evolution and Particle Swarm Optimization algorithms in training of feed-forward neural network for stock price prediction", Informatics and Systems (INFOS), 2010 The 7th International Conference on 28 Mar 2010, IEEE, pp. 1-8.

[48] M. Rout, B. Majhi, R. Majhi, G. Panda, "Forecasting of currency exchange rates using an adaptive ARMA model with differential evolution based training", Journal of King Saud UniversityComputer and Information Sciences, vol. 26, no. 1, pp. 7-18, 31 Jan 2014.

[49] N. Hachicha, B. Jarboui, P. Siarry, "A fuzzy logic control using a differential evolution algorithm aimed at modelling the financial market dynamics", Information Sciences, vol. 181, no. 1, pp. 79-91, 1 Jan 2011

[50] N. Barberis, R. Thaler, "A survey of behavioral finance", Handbook of the Economics of Finance, vol. 1, pp. 1053-1128, 31 Dec 2003.

[51] D. Hirshleifer, "Investor psychology and asset pricing", The Journal of Finance, vol. 56, no. 4, pp. 1533-1597, 1 Aug 2001.
[52] K. Price, R. M. Storn, J. A. Lampinen, "Differential evolution: a practical approach to global optimization", Springer Science \& Business Media, 4 Mar 2006.

[53] M. Y. Cheng, N. D. Hoang, Y. W. Wu, "Hybrid intelligence approach based on LS-SVM and Differential Evolution for construction cost index estimation: A Taiwan case study", Automation in Construction, vol. 35, pp. 306-313, 30 Nov 2013.

[54] P. Mohapatra, A. Raj, T. K. Patra, "Indian Stock Market Prediction Using Differential Evolutionary Neural Network Model", International Journal of Electronics Communication and Computer Technology (IJECCT), Vol. 2, 2012.

[55] W. Shen, X. Guo, C. Wu, D. Wu, "Forecasting stock indices using radial basis function neural networks optimized by artificial fish swarm algorithm", Knowledge-Based Systems, vol. 24, no. 3, pp. 378-85, 30 Apr 2011

[56] X. L Li, Z. J. Shao, J. X. Qian, "An optimizing method based on autonomous animats: fish-swarm algorithm", System Engineering Theory and Practice, vol. 22, no. 11, pp. 32-38, Nov 2002.

[57] D. Niu, W. Shen, Y. Sun, "RBF and Artificial Fish Swarm Algorithm for short-term forecast of stock indices", Communication Systems, Networks and Applications (ICCSNA), 2010 Second International Conference on 29 Jun 2010, IEEE, vol. 1 , pp. 139-142.

[58] M. Li, F. Suohai, "Forex prediction based on SVR optimized by artificial fish swarm algorithm", Intelligent Systems (GCIS), 2013 Fourth Global Congress on 3 Dec 2013, IEEE, pp. 47-52.

[59] T. J. Hsieh, H. F. Hsiao, W. C. Yeh, "Forecasting stock markets using wavelet transforms and recurrent neural networks: An integrated system based on artificial bee colony algorithm", Applied soft computing, vol. 11, no. 2, pp. 2510-2525, 31 Mar 2011.

[60] B. Basturk, D. Karaboga, "An artificial bee colony (ABC) algorithm for numeric function optimization", IEEE swarm intelligence symposium, vol. 8, no. 1, pp. 687-697, 12 May 2006.

[61] D. Karaboga, B. Basturk, "A powerful and efficient algorithm for numerical function optimization: artificial bee colony ( $\mathrm{ABC}$ ) algorithm", Journal of global optimization, vol. 39, no. 3, pp. 459471, 1 Nov 2007

[62] D. Karaboga, B. Basturk, "On the performance of artificial bee colony (ABC) algorithm", Applied soft computing, vol. 8, no. 1, pp. 687-697, 31 Jan 2008.

[63] D. Karaboga, B. Akay, "A comparative study of artificial bee colony algorithm", Applied mathematics and computation, vol. 214, no. 1, pp. 108-132, 1 Aug 2009.

[64] E. Nourani, A. M. Rahmani, A. H. Navin, "Forecasting stock prices using a hybrid artificial bee colony based neural network", Innovation Management and Technology Research (ICIMTR), 2012 International Conference on 21 May 2012, IEEE, pp. 486-490.

[65] M. Rout, B. Majhi, U. M. Mohapatra, R. Mohapatra, "An artificial bee colony algorithm based efficient prediction model for stock market indices", Information and Communication Technologies (WICT) 2012, World Congress on 30 Oct 2012, IEEE, pp. 750-754.

[66] R. C. Brasileiro, V. L. F. Souza, B. J. T Fernandes, A, L. I. Oliveira, "Automatic method for stock trading combining technical analysis and the Artificial Bee Colony Algorithm" Evolutionary Computation (CEC) 2013, IEEE Congress on 20 Jun 2013, pp. 1810-1817.

[67] L. A. Teixeira, A. L. I. D. Oliveira, "A method for automatic stock trading combining technical analysis and nearest neighbor classification", Expert systems with applications, vol. 37, no. 10, pp. 6885-6690, 31 Oct 2010.

[68] Z. Mustaffa, Y. Yusof, "A hybridization of enhanced artificial bee colony-least squares support vector machines for price forecasting", Journal of Computer Science, vol. 8, no. 10, pp. 1680-1690, 2012.

[69] K. N. Devi, V. M. Bhaskaran, G. P. Kumar, "Cuckoo optimized SVM for stock market prediction", Innovations in Information, Embedded and Communication Systems (ICIIECS) 2015, International Conference on 19 Mar 2015, IEEE, pp. 1-5.

[70] X. S. Yang, S. Deb, "Cuckoo search via Lévy flights", Nature \& Biologically Inspired Computing, (NaBIC) 2009, World Congress on 9 Dec 2009, IEEE, pp. 210-214.

[71] Y. Feng, G. G. Wang, Q. Feng, X. J. Zhao, "An effective hybrid cuckoo search algorithm with improved shuffled frog leaping algorithm for 0-1 knapsack problems", Computational intelligence and neuroscience, Article no. 36, 1 Jan 2014.

[72] O. Hegazy, O. S. Soliman, M. A. Salam, "Comparative study between FPA, BA, MCS, ABC, and PSO algorithms in training and optimizing of LS-SVM for stock market prediction", International 
Journal of Advanced Computer Research, vol. 5, no. 18, pp. 35-45, 1 Mar 2015.

[73] X. S. Yang, "A new metaheuristic bat-inspired algorithm”, Nature inspired cooperative strategies for optimization (NICSO), Springer Berlin Heidelberg, pp. 65-74, 2010.

[74] S. Mishra, K. Shaw, D. Mishra, "A new meta-heuristic bat inspired classification approach for microarray data", Procedia Technology, vol. 4, pp. 802-806, 1 Jan 2012.

[75] R. Hafezi, J. Shahrabi, E. Hadavandi, “A bat-neural network multiagent system (BNNMAS) for stock price prediction: Case study of DAX stock price", Applied Soft Computing, vol. 29, pp. 196-210, 30 Apr 2015.

[76] A. Ochoa, L. Margain, A. Hernández, J. Ponce, A. D. Luna, A. Hernández, O. Castillo, "Bat Algorithm to improve a financial trust forest", Nature and Biologically Inspired Computing (NaBIC) 2013, World Congress on 2013, IEEE, pp. 58-62, Aug 2012.

[77] S. J. Nanda, "A WNN-CSO model for accurate forecasting of chaotic and nonlinear time series", Signal Processing, Informatics, Communication and Energy Systems (SPICES) 2015, International Conference on 19 Feb 2015, IEEE, pp. 1-5.

[78] S. C. Chu, P. W. Tsai, "Computational intelligence based on the behavior of cats", International Journal of Innovative Computing, Information and Control. Vol. 3, no. 1, pp. 163-173, 1 Feb 2007.

[79] G. Panda, P. M. Pradhan, B. Majhi, "Direct and inverse modeling of plants using cat swarm optimization", Handbook of Swarm Intelligence, Springer Berlin Heidelberg, pp. 469-485, 2011.

[80] Y. Chen, B. Yang,J. Dong, "Time-series prediction using a local linear wavelet neural network", Neurocomputing, vol. 69, no. 4, pp. 449-465, 31 Jan 2006.

[81] J. C. Patra, A. C. Kot, "Nonlinear dynamic system identification using Chebyshev functional link artificial neural networks", IEEE Transactions on Systems, Man, and Cybernetics, Part B (Cybernetics). Vol. 32, no. 4, pp. 505-511, Aug 2002. 